\title{
NORADRENERGIC RESPONSES OF SPINAL NEURONS IN LOCUS COERULEUS-SPINAL CORD CO-CULTURES ${ }^{1}$
}

\author{
RAYMUND Y. K. PUN,* KENNETH C. MARSHALL, $\ddagger$ WALTER J. HENDELMAN,§ \\ PETER B. GUTHRIE, ${ }^{*}$ AND PHILLIP G. NELSON* \\ * Laboratory of Developmental Neurobiology, National Institute of Child Health and Human Development, National Institutes of \\ Health, Bethesda, Maryland 20205 and the Departments of $\ddagger$ Physiology and $\$$ Anatomy, School of Medicine, University of \\ Ottawa, Ottawa K1H 8M5, Ontario, Canada
}

Received March 5, 1984; Revised July 2, 1984; Accepted July 23, 1984

\begin{abstract}
Locus coeruleus (LC) explants were co-cultured with dissociated spinal neurons of mice. Nerve fibers exhibiting catecholamine fluorescence radiated from the explants and frequently invested spinal cord (SC) neurons close to the explants. Electrical stimulation of the explant and iontophoretic application of norepinephrine evoked a spectrum of slow depolarizing, hyperpolarizing, and biphasic responses in the SC cells. The responses to LC stimulation and to application of norepinephrine were usually similar in a given cell. The depolarizing responses were associated with an increase in apparent input resistance and pharmacologic tests indicated that the responses were mediated by $\alpha$-receptors. Neurons in regions innervated by catecholaminecontaining fibers usually gave depolarizing responses to LC stimulation and such neurons had a very high probability of exhibiting depolarizing responses to applied norepinephrine. It would appear that either locus coeruleus explants favored the survival of cells with $\alpha$-receptors or expression of these receptors in SC neurons was induced by innervation of the neurons by locus coeruleus axons.
\end{abstract}

As the largest of the noradrenergic nuclei in mammalian brains, the locus coeruleus (LC) has recently been the object of many investigations (see reviews by Amaral and Sinnamon, 1977; Foote et al., 1983). The application of histofluorescence and immuocytochemical techniques has contributed greatly to an understanding of the morphology of this nucleus and its projections. However, the cellular actions of LC innervation on target neurons are still poorly understood. Neurons in most target areas of the LC projections have been reported to be depressed following LC stimulation. These include cerebellum (Siggins et al., 1971a), hippocampus (Segal and Bloom, 1974), cerebral cortex (Phillis and Kostopoulos, 1977), spinal trigeminal nucleus (Sasa et al., 1974), and the spinal cord (Pearson et al., 1978; Hodge et al., 1981). Conversely, facilitatory effects of LC stimulation have been observed in studies of relay neurons of the lateral geniculate nucleus (Rogawski and Aghajanian, 1982) and in other studies of the spinal cord (Strahlendorf et al., 1980; Fung and Barnes, 1981). The actions of locally applied norepinephrine (NE) are also variously reported as depressant or excitatory, depending on the types of neurons studied, and other experimental variables (see Szabadi, 1979 for a review).

LC neurons have been grown in explant cultures by various

${ }^{1}$ We are grateful to Mrs. S. Fitzgerald for preparing the cultures, Ms. L. Bowers and Mr. S. Neal for helping with the photography, and Mrs. M. Schaefer for preparing and typing the manuscript. Our thanks to the following companies for their generous donation of the chemicals: desmethylimipramine, USV Pharmaceutical Corporation; piperoxan, Rhône Poulenc Santé; phentolamine, CIBA Pharmaceutical Company; phenoxybenzamine, Smith, Kline and French Laboratories. groups (Schlumpf et al., 1977; Victorov et al., 1978; Olson et al., 1979; Hendelman et al., 1982), and in some cases have been co-cultured with explants of target nuclei (Dreyfus et al., 1979; Marshall and Garber, 1983). The co-culturing of LC with target tissue offers the important advantages of an in vitro system for the study of actions and mechanisms of the transmitter released from LC neurons. It is also apparent, however, that cultures of dissociated neurons are advantageous for intracellular recordings and detailed studies of transmitter actions. It is possible to position the electrodes at various locations over the cell under visual control. This enables experimenters to record from any cell they choose, plus the possibility of detailed mapping of sensitive areas on the cell to the transmitter under investigation. The culture system further offers the advantage of allowing the immediate environment of the cell under observation to be altered (e.g., by a perfusion pipette). We have grown co-cultures of dissociated spinal neurons (as described and studied by Ransom et al., 1977), with explants containing LC neurons (Hendelman et al., 1982) which could be electrically stimulated to simulate activation of a coeruleo-spinal pathway.

The selection of spinal neurons as a target tissue in this study is also appropriate because the coeruleo-spinal pathway in animals has been described and characterized (Nygren and Olson, 1977; Commissiong et al., 1978; Westlund and Coulter, 1980; Commissiong, 1981). The actions of catecholamines on spinal neurons and their possible functional roles have also been widely studied and recently reviewed (Marshall, 1983).

Preliminary reports of these studies have been given (Marshall et al., 1981; Pun et al., 1981).

\section{Materials and Methods}

Tissue culture. Explants from the LC region were obtained from C57BL/6J mice at term or within $12 \mathrm{hr}$ after birth, using methods 


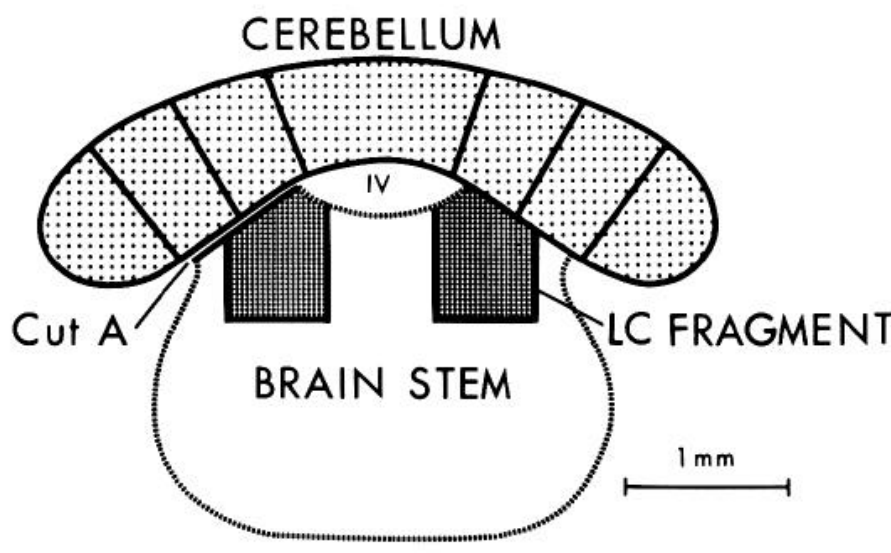

Figure 1. Diagrammatic representation of brain stem section from which the LC was dissected. $I V$ denotes the fourth ventricle. See the text for description of isolating the LC pieces.

similar to that of Hendelman et al. (1982). Narcosis was induced in a closed chamber containing dry ice and was followed by cardiac puncture. The segment of brain from the spinal cord junction to the midcerebral hemisphere level was removed and the pia was stripped from the cerebellar surface. The cerebellum and underlying pontine region were isolated as a single transverse slab (Fig. 1) by cutting parallel to the superior and inferior margins of the cerebellum. The LC fragment was isolated by trimming away brain stem tissue from medial, lateral, and basal aspects and was finally detached from the cerebellum (cut $A$ in Fig. 1) and placed in a $35-\mathrm{mm}$ Falcon culture dish. The selection of the fragment explanted for these experiments was influenced by our desire to include the ventral part of LC that has been shown to project to the spinal cord (e.g., Satoh et al., 1977; Westlund and Coulter, 1980).

In most cases, the explant was placed directly on the collagen-coated surface of the culture dish, fed with a single drop of growth medium ( $10 \%$ fetal bovine and $10 \%$ horse serum in minimal essential medium), and incubated in a humidified $\mathrm{CO}_{2}$ incubator. The following day, freshly dissociated spinal cord tissue from 13-day fetal mice was added to the culture dish containing the LC fragment. In an alternate procedure, explants were placed directly into a culture dish containing dissociated spinal cord that had been plated 2 weeks earlier. Displacement and floating of the explant were more frequent with the latter procedure and it was not often used.

The spinal cord with dorsal root ganglion tissue was dissociated according to a previously published procedure (Ransom et al., 1977) except that the freshly minced cords were incubated with $0.25 \%$ trypsin for $30 \mathrm{~min}$ before transfer to growth medium and triturating. Those cultures in which spinal cord was added to the day-old explant were grown in $10 \%$ fetal bovine, $10 \%$ horse serum in minimal essential medium for the first 8 days, and the antimitotic agent $5^{\prime}$-fluoro- $2^{\prime}$ deoxyuridine (FdU) was added during days 7 and 8 . Thereafter, the growth medium was $10 \%$ horse serum in minimal essential medium. In those instances where the explants were added to 2-week-old spinal cord, the explants were not exposed to fetal calf serum or FdU, since these stages were completed before the explanting procedure. Cultures were used for electrophysiologic studies when the spinal cord tissue was a minimum of 25 days in culture, and for fluorescence microscopy when the LC explant was at least 2 weeks in culture.

Fluorescence microscopy. Catecholamine fluorescence was obtained by the method of Bloom and Battenberg (1976). The cultures were rinsed in balanced salt solution and bathed in $2 \%$ glyoxylic acid for 10 min at about $2^{\circ} \mathrm{C}$, followed by drying in a warm air stream and oven heating. An oven temperature not higher than $92^{\circ} \mathrm{C}$ was used to avoid distortion of the plastic culture dishes. The resulting material was viewed and photographed using a Zeiss microscope with epi-illumina-
Figure 2. Photographic montage of fluorescent LC explant. See the text for description. Calibration: $100 \mu \mathrm{m}$.

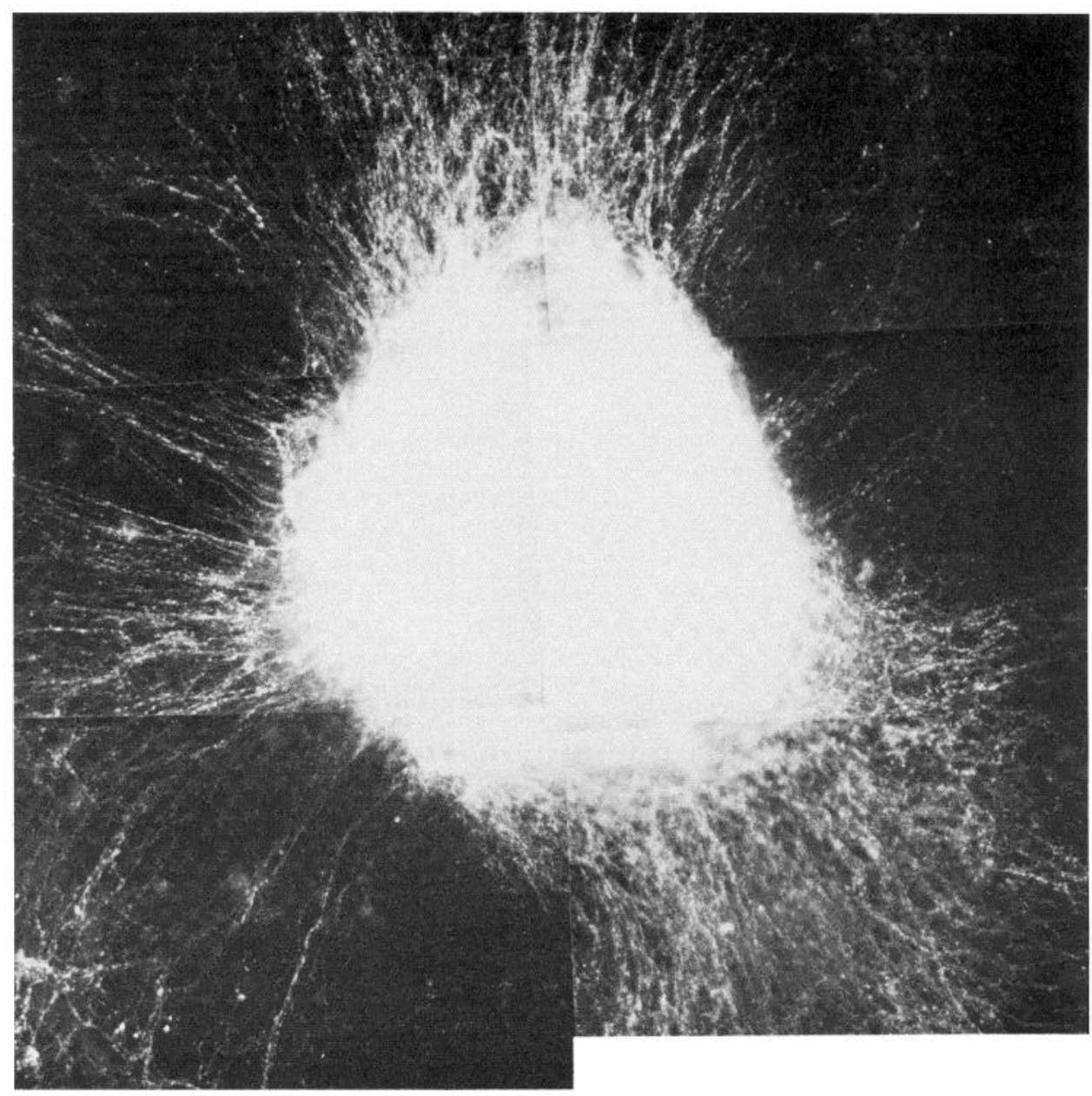


a
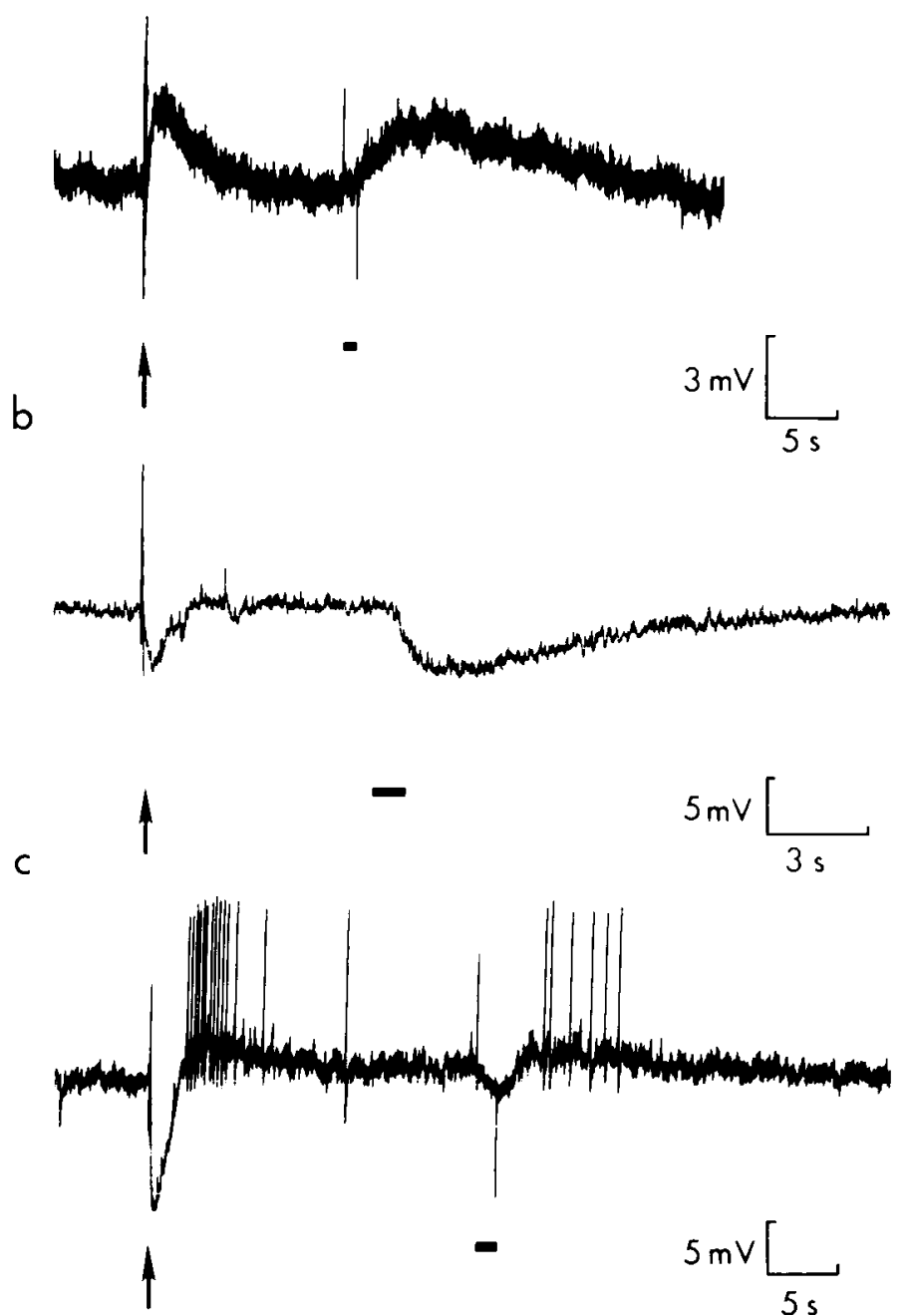

Figure 3. Chart recordings of responses to exogenously applied norepinephrine (solid bars) and explant stimulation (arrows) in three different cells. In each case, the response elicited by the two types of stimulation was similar. $a$, SC cell exhibiting depolarizing responses; $b$, $\mathrm{SC}$ cell exhibiting hyperpolarizing responses; $c, \mathrm{SC}$ cell exhibiting biphasic responses consisting of a hyperpolarization followed by a depolarization. Note the generation of action potentials (chopped by frequency response of the pen recorder) during the depolarizing phase. NE was applied by iontophoresis in cases $a$ and $c$, and by pressure pipette in case $b$.

tion and an 018 Zeiss fluorescence filter set. With filters, the fluorescent fibers had a crisp blue color. The same field could also be viewed and photographed using phase contrast, though cell morphology was distorted by the drying and baking procedures.

Electrophysiology. Most electrophysiology experiments were conducted with the cultures bathed in growth medium, though some were carried out in minimal essential medium (MEM) with $2.5 \%$ horse serum. The major ionic composition of the medium was as follows: $\mathrm{Na}^{+}, 161 \mathrm{mM} ; \mathrm{K}^{+}, 5.4 \mathrm{mM} ; \mathrm{Ca}^{2+}, 1.8 \mathrm{mM} ; \mathrm{Mg}^{2+}, 0.8 \mathrm{mM} ; \mathrm{Cl}^{-}, 120 \mathrm{mM}$; $\mathrm{HCO}_{3}{ }^{-}, 44 \mathrm{mM}$. It was our impression that responsiveness of the cells to norepinephrine (NE) was not as well maintained in the absence of serum. It may be that changing the growth medium into recording medium caused the release of NE from terminals, depleted the releasable pool of NE, and induced desensitization of the receptors, thereby leading to a less maintained NE response. More experiments will be required to determine the effect of serum on responses to NE. The culture dish was mounted in a chamber on the stage of an inverted phase-contrast microscope. The bathing solution was covered with a layer of mineral oil to prevent evaporation. Equal molar concentrations of $\mathrm{Ca}^{2+}$ and $\mathrm{Mg}^{2+}$ ( 3 to $5 \mathrm{~mm}$ ) were usually added to reduce the background spontaneous activity of the SC cells. Temperature of the bathing solution was maintained at 35 to $37^{\circ} \mathrm{C}$ and $\mathrm{pH}$ was kept at a constant physiologic level by a stream of $\mathrm{CO}_{2}$ :air (5:95\%) directed across the top of the culture dish.

Electrical stimulation of the explant was by a glass pipette broken back to a tip diameter of about $10 \mu \mathrm{m}$, filled with $0.15 \mathrm{M} \mathrm{NaCl}$ in $1.5 \%$ agar. These electrodes, having DC resistances of about 10 megaohms were placed to touch the surface in the central part of the explant. Usual stimulus parameters were $1 \mathrm{msec}, 10-$ to $25-\mathrm{V}$ bipolar pulses, either single or in trains of three or five, through a stimulus isolation unit. In trains, the period of the bipolar pulses was $25 \mathrm{msec}$.

Intracellular recording of spinal cord neurons was accomplished with $3 \mathrm{M}$ potassium acetate-filled glass pipettes having resistances of 35 to 80 megaohms. A bridge circuit was used for intracellular current injection during recordings. Continuous recordings of intracellular potentials and injected currents were made on a pen recorder, though signals with high frequency components such as resistance-measuring pulses were recorded on oscillographic film.

Drugs were applied to cells to determine whether they were influenced by $\mathrm{NE}$ and whether responses to explant stimulation or $\mathrm{NE}$ application could be altered by substances known to interact with noradrenergic systems. In the initial experiments, all drugs were applied by pressure from glass pipettes having outside tip diameters of 6 to 10 $\mu \mathrm{m}$. In later experiments, constituting some $90 \%$ of cells analyzed, NE was applied iontophoretically from micropipettes having tip diameters of $<1 \mu \mathrm{m}$ containing 0.05 to $0.2 \mathrm{M}$ freshly made NE (frec base, Sigma) at $\mathrm{pH} 5$ to 6 .

When applied by perfusion pipettes, balanced salt solution, MEM (without serum), or bathing medium was the svehicle for pressureapplied substances. Ascorbate $\left(10^{-4} \mathrm{M}\right.$, Sigma) was present in the medium to prevent the oxidation of NE $\left(10^{-5} \mathrm{M}\right)$ solution. The $\mathrm{pH}$ of the solution was buffered to about 7.3. In iontophoretic experiments, a retaining current $(-10$ to $-25 \mathrm{nA})$ was applied to prevent leakage of drug into the medium. During ejection period ( +40 to $+150 \mathrm{nA}, 1$ to 15 sec) a current of equal and opposite polarity was automatically passed through another agar bridge into the bath so that the total current flowing through the bath was zero at all times. For the majority of studies, a current of less than $+100 \mathrm{nA}$ for a duration of 2 to $3 \mathrm{sec}$ was used to evoke a response. The NE-induced response always outlasted the period of application, indicating that the response did not arise

TABLE I

Cells exhibiting different categories of responses to iontophoretically applied $N E$ in the presence and absence of explant

\begin{tabular}{|c|c|c|c|c|c|}
\hline & \multicolumn{5}{|c|}{ Response to NE } \\
\hline & Depolarization & Hyperpolarization & Biphasic & None & Total \\
\hline \multicolumn{6}{|l|}{ With explant } \\
\hline Away from explant $(>1 \mathrm{~cm})$ & 36 & 14 & 1 & 67 & 118 \\
\hline & $31 \%$ & $12 \%$ & $1 \%$ & $57 \%$ & \\
\hline Total & $\begin{array}{c}137 \\
30 \%\end{array}$ & $\begin{array}{c}38 \\
8 \%\end{array}$ & $\begin{array}{c}10 \\
2 \%\end{array}$ & $\begin{array}{l}275 \\
60 \%\end{array}$ & 460 \\
\hline
\end{tabular}


TABLE II

Responsiveness to applied NE

Results were evaluated by Student's $t$ test.

\begin{tabular}{ccc}
\hline A. & $\begin{array}{c}\text { Responsive } \\
\text { Cells }\end{array}$ & $\begin{array}{c}\text { Nonresponsive } \\
\text { Cells }\end{array}$ \\
\hline Absence of explant & 47 & 97 \\
Presence of explant & $(33 \%)$ & $(67 \%)$ \\
& 185 & 275 \\
& $(40 \%)$ & $(60 \%)$ \\
B. & & $p>0.05$ \\
\hline Absence of explant & Depolarizing & Hyperpolarizing \\
& Response & Response \\
\hline Presence of explant & 20 & 22 \\
& $(48 \%)$ & $(52 \%)$ \\
& 137 & 38 \\
& $(78 \%)$ & $(22 \%)$ \\
& & $p<0.01$ \\
\hline
\end{tabular}

TABLE III

Correlation of evoked responses

Evaluation was by $\chi^{2}$ test, $p<0.001$, for both A and B.

\begin{tabular}{lcc}
\hline & \multicolumn{2}{c}{ Explant Stimulation } \\
\cline { 2 - 3 } & Response & $\begin{array}{c}\text { No } \\
\text { Response }\end{array}$ \\
\hline A. NE application & & \\
Response & 103 & 22 \\
No response & 19 & 189 \\
\hline & \multicolumn{2}{c}{ Explant Stimulation } \\
\cline { 2 - 3 } & Depolarization $\quad$ Hyperpolarization \\
\hline B. NE Application & & \\
Depolarization & 87 & 2 \\
Hyperpolarization & 4 & 10 \\
\hline
\end{tabular}

from a current effect. Furthermore, a current of equal intensity but opposite polarity through the drug barrel did not cause any obvious effect on the membrane potential of the cell under recording.

Following electrophysiologic experiments, cultures were routinely stained for catecholamine fluorescence and the presence of fluorescent fibers in the region of individual spinal neurons from which recordings had been made was noted.

\section{Results}

Explants were monitored under low power phase microscopy, and were observed to assume a rounded or oval shape and to develop zones of radial streaming within a few days of explanting. The thick part of the explant was less than $1 \mathrm{~mm}$ in diameter and usually measured 0.6 to $0.8 \mathrm{~mm}$ in its longest and 0.5 to $0.7 \mathrm{~mm}$ in its shortest diameter. The streaming was sometimes quite symmetrical but more often was absent from some parts of the circumference of the explant, light in other parts, and heavier in others. Occasionally one or a few fibers with distinct edges were observed to be radially oriented to the explant, and were judged to be myelinated axons.

In an initial series of experiments, more than 50 explants ranging in age (in vitro) from 2 to 6 weeks were observed with fluorescence microscopy after staining with the glyoxylic acid procedure. In all but three (two of which were small and thin explants), bright fluorescence attributable to catecholamines was observed within the explant and in fibers radiating from it. Within the explant, individual fluorescing cell bodies were usually not distinguishable, and the only features of note were that there were sometimes regions of very bright catecholamine fluorescence while other areas appeared devoid of it, and that there were frequently bright bands of fluorescence that coursed around some parts of the circumference of the explants. 'T'he fibers that radiated from the explant usually followed a rather straight course for about the first $0.5 \mathrm{~mm}$ (Fig. 2). Beyond this, the radial streaming was absent, but fluorescent fibers having characteristic varicosities could be observed at distances up to 1.5 to $2.5 \mathrm{~mm}$ from the explant. The radiating fibers were usually not symmetrically arranged, and were found to follow the streaming patterns observed with phase microscopy. The fluorescent fibers further from the explant appeared randomly arranged in a plexus, sometimes thick and sometimes very sparse. Within the moderate zones of the plexus, it could be observed that there was frequently an intense ramification of fluorescent fibers within and around clumps of spinal cord cells. It was a frequent observation that the density of spinal neurons was less in the region close to the explant $(0.5$ to $1 \mathrm{~mm}$ from the edge) than in more distant locations.

Responses of spinal cord neurons to LC stimulation and to $N E$ application. Flectrical stimulation of the brain stem explant usually resulted in some alteration of membrane potential or electrical activity in spinal neurons located within about $2 \mathrm{~mm}$ from the margins of the explant. In some cases, changes were observed only within a relatively short latency from the termination of the stimulus train. Such short latency effects ( 1 to $2 \mathrm{msec}$ ) included action potentials, fast depolarizing and hyperpolarizing events which resembled synaptic potentials and somewhat longer depolarizing (16 cells) or hyperpolarizing "tails" ( 33 cells) of a few hundred-msec duration. The hyperpolarizing responses of this type were sometimes shown to be increased by intracellular injection of depolarizing current and decreased by hyperpolarizing current, and might have been spike afterhyperpolarizations or summated inhibitory postsynaptic potentials (IPSPs).

Another frequently observed result of the explant stimulation was the generation of synaptic or action potentials during a relatively long time course following the stimulation. On about 30 cells, action potentials were evoked during a slower depolarizing response, and it was difficult to ascertain whether they were simply a consequence of that depolarization. In another 14 cells, however, they occurred in the absence of a depolarizing response or with a quite different time course, and appeared to be due to polysynaptic effects of the stimulation. Similarly, IPSPs (about 21 cells) and EPSPs (about 19 cells), and a mixture of EPSPs and IPSPs (about 11 cells) were sometimes evoked in long trains and these could occur in the absence of any apparent direct monosynaptic response, or in conjunction with a hyperpolarizing or depolarizing response.

In approximately $40 \%$ of the spinal neurons tested ( $n=112$, see Table IIIA), longer latency (10 to $100 \mathrm{msec}$ ) and duration depolarizations or hyperpolarizations were observed following explant stimulation, and it is these responses to which we attended particularly and to which the following descriptions apply. The precise latency to onset of these slower responses was difficult to define because of the shorter latency responses and because trains of electrical stimuli were usually used. The most frequently observed response (91 cells, see Table $3 B$ ) was a slow depolarization which rose with a slow time course, reaching a peak of between 1 and $5 \mathrm{mV}$ at between 0.7 and 1.5 sec following the stimulus (Fig. $3 a$ ). These events typically had a decay time considerably longer than their rise time, with the duration ranging from 2 to $20 \mathrm{sec}$. Graded amplitudes of the responses could be observed by either altering the number of stimuli in the train, or the strength of the stimulation (see Marshall et al., 1981).

Slow hyperpolarizing responses to explant stimulation were observed much less frequently, i.e., in about $11 \%$ of the spinal neurons tested ( $n=12$, see Table IIIB). These responses had shorter rise times (less than $1 \mathrm{sec}$ ) and shorter durations (1.5 to $3 \mathrm{sec}$ ) than the depolarizations (Fig. $3 b$ ). In even fewer cells $(n=9)$, biphasic responses were observed which appeared to 

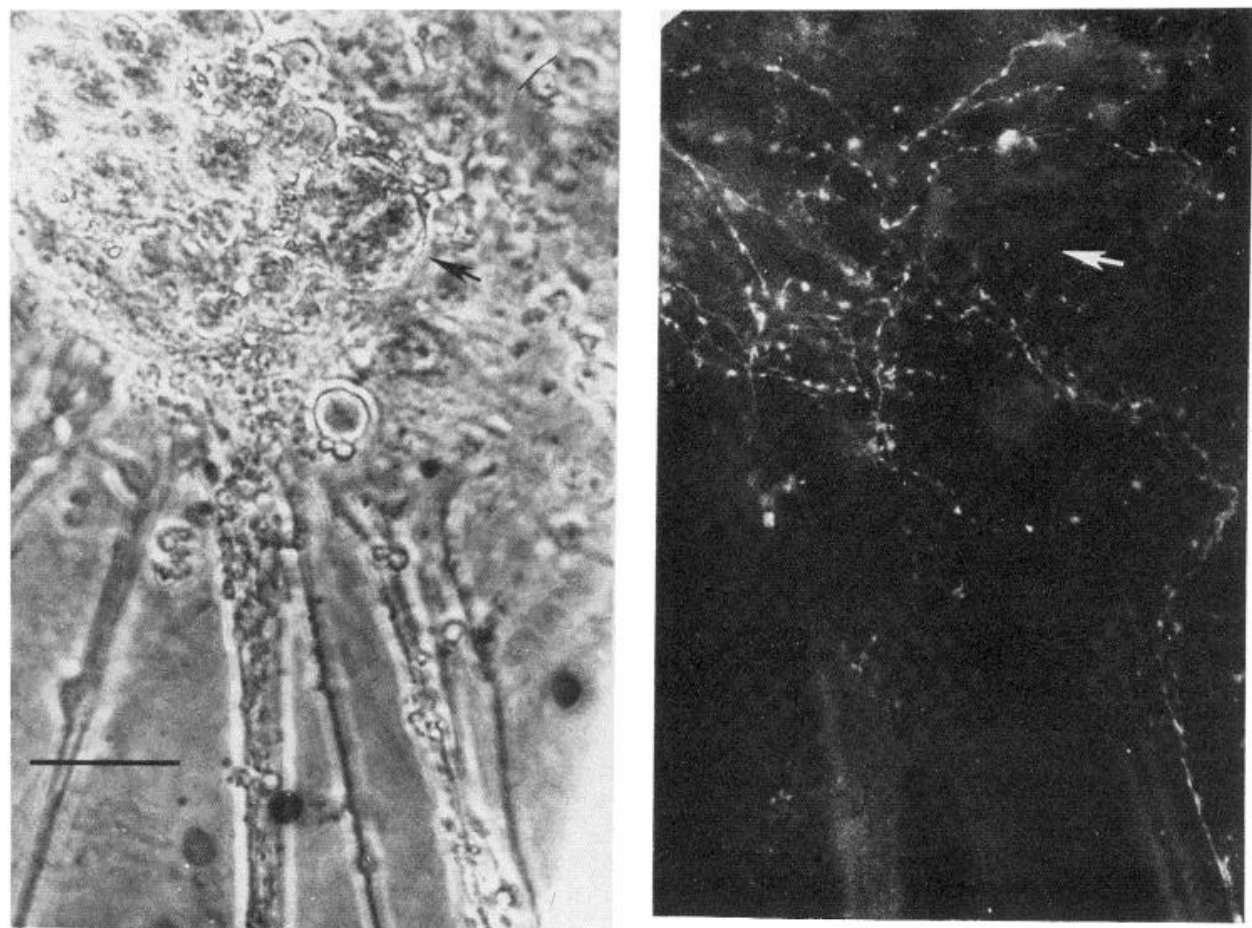

Figure 4. Correlation of responsive cell and presence of fluorescent fibers. Left, A phase contrast photomicrograph of a cell which responded to explant stimulation (arrowed). Subsequent staining of the plate indicates the presence of fluorescent fibers around the responsive cell (right). Arrow indicates the approximate location of the cell. Note the fluorescent fiber entering the island of cells from bottom right of the photomicrograph. Calibration bar: $50 \mu \mathrm{m}$ for both photomicrographs. The bottom trace shows chart recordings of the response to explant stimulation (arrows) and to NE application (bars). Both stimuli evoked depolarization of the cell. Same cell as shown in Figure 9.

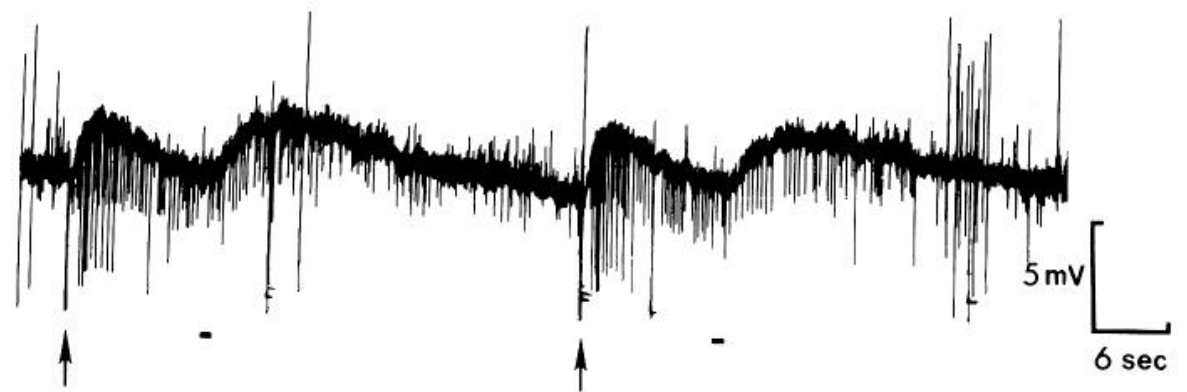

be a combination of the hyperpolarizing and depolarizing responses described (Fig. $3 c$ ). In each case, the hyperpolarizing phase preceded the depolarization.

About $40 \%$ of the neurons tested (see Tables I and II) showed a reproducible response to $\mathrm{NE}$ application, and these responses were of three types, closely resembling those elicited by explant stimulation. The hyperpolarizing responses $(3$ to $10 \mathrm{mV})$ were of relatively short duration, with the membrane potential increasing smoothly during the $\mathrm{NE}$ application and the return toward the baseline occurring at about the end of the application or shortly afterward. The depolarizing responses to NE were of considerably longer duration. Iontophoretic applications of about 2 -sec duration typically resulted in depolarizations of 3 to $5 \mathrm{mV}$, with the peak amplitude occurring about 5 sec after the termination of the application, and having a total duration of about $25 \mathrm{sec}$. The biphasic responses had an initial hyperpolarizing phase which was succeeded by a slow depolarization very similar in appearance to those just described. Examples of these different types of responses recorded in three different cells and elicited by the two types of stimulation are shown in Figure 3.

The incidence of the various types of neuronal responses to applied NE in different kinds of cultures is shown in Table I. Dissociated spinal cord (SC) cells were grown in either the absence or presence of LC explants. Data obtained from the SC-LC co-cultures are subdivided into results obtained from $\mathrm{SC}$ neurons located close to $(<2 \mathrm{~mm})$ or far from $(>1 \mathrm{~cm})$ the LC explant.
The absence or presence of the explant did not appear to have a dramatic effect on the presence or absence of response to applied NE in SC neurons. As shown in Table IIA, there was a slightly greater incidence of responsive cells when the culture included the explant, but this was not statistically significant.

When the nature of the response to $\mathrm{NE}$ was taken into account, however, a significant effect of LC co-culture was noted (Table IIB). Responsive cells were much more likely to give a depolarizing response in the presence of the explant. Thus, less than half of the responsive neurons gave a depolarizing response in the absence of the explant, while over threefourths gave such a response in the presence of the explant. These differences were statistically highly significant.

When those cells tested with both LC stimulation and NE application were considered, a high degree of concordance between the two types of tests was seen with regard to the responding (either depolarizing or hyperpolarizing responses) versus nonresponding cells (Table IIIA). That is, cells that responded to one type of stimulation also tended to respond to the other, while those cells that did not respond to one type also failed to respond to the other. This concordance was further emphasized if the nature of the response was taken into account (Table IIIB). The type of response (depolarizing or hyperpolarizing) tended to be the same for the two types of stimulation (see Fig. 3), and only about $5 \%$ of this population of neurons had discordant responses for the two types of stimulation. 
CON

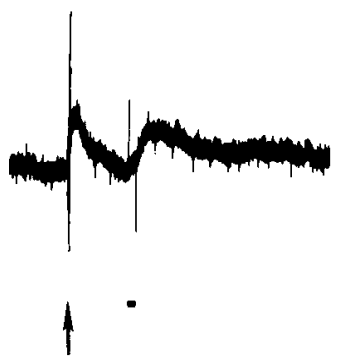

DEPOL $\quad 0.35 \mathrm{nA}$
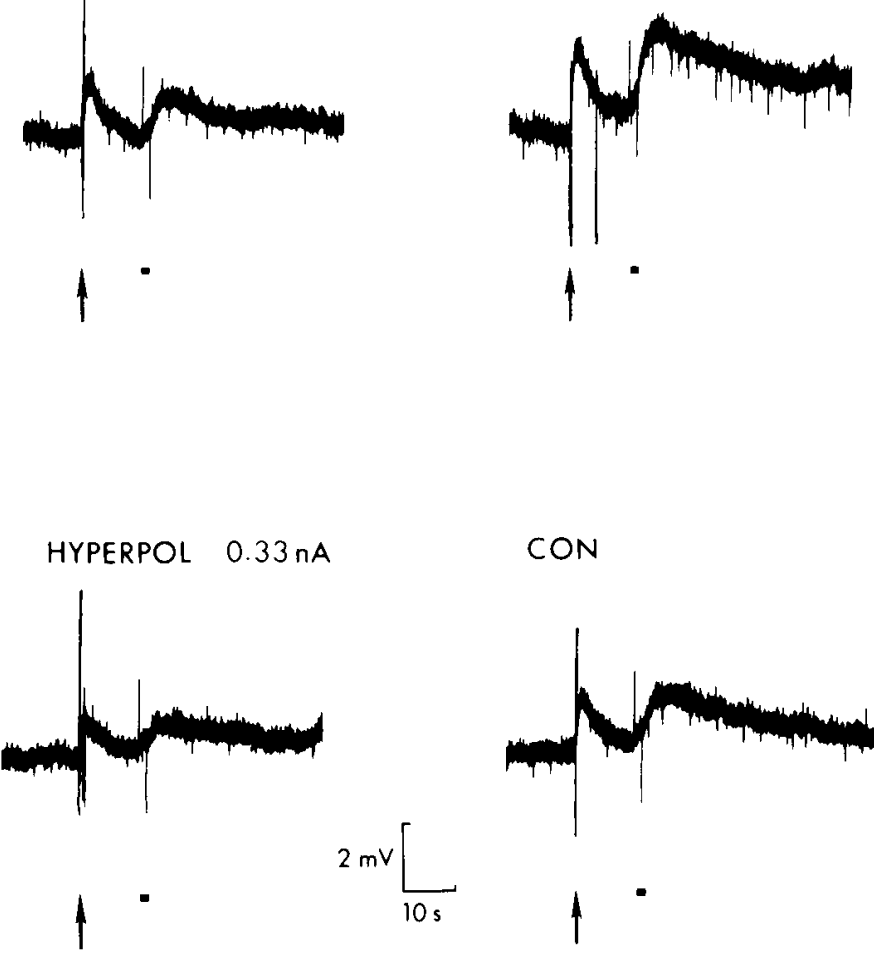

Figure 5. Effects of current injection on responses evoked by explant stimulation (arrows) and iontophoretically applied NE (solid bars). The depolarizing responses were augmented when depolarizing current was injected into the cell ( $D E P O L)$, and were reduced when hyperpolarizing current was injected (HYPERPOL). CON, control.

A revealing set of experiments resulted from an early attempt to define the cultures by taking a smaller explant from a more lateral location within the brain stem. In each of the seven experiments with the resulting co-cultures, the result was the same; there were very few depolarizing responses to explant stimulation or to NE application. Also, subsequent staining for catecholamine fluorescence showed that in five of these cultures there was no specific fluorescence, while in two, there were only a few fibers in regions remote from where the recordings had been made.

Conversely, the observation of depolarizing responses to explant stimulation and NE application in spinal neurons was usually correlated with the presence of adjacent catecholaminestaining fibers, as seen in the subsequently stained preparation. An example of the investment of responsive cells by catecholamine containing fibers is shown in Figure 4. In some cultures in which the spread of catecholamine-containing fibers from the explant was not symmetrical, fibers were observed in regions of spinal neurons from which several depolarizing responses had been obtained, while they were absent from regions in which such responses had not been observed.

Dorsal root ganglion cells. Among the dissociated neurons that were studied electrophysiologically, 10 were judged to be dorsal root ganglion cells on the basis of morphology, absence of ongoing synaptic activity, and spike shape (Ransom et al., 1977; Peacock et al., 1973). In this group of cells, no responses to NE were observed except a few that were attributable to artifacts of pressure application. The only responses to stimulation of the explant were short latency-evoked action potentials. In some cases, it seemed probable that these spikes were antidromically activated on the basis of (1) following of high frequency stimulation and (2) an abrupt rise from a low-noise base line. In some cases, the spikes were followed by rather prominent hyperpolarizations that appeared to be after-hyperpolarizations (Ransom et al., 1977).

Electrophysiologic and pharmacologic testing of the depolarizing responses. The depolarizing responses of spinal neurons to stimulation of the brain stem explant and to NE application were thus similar in time course and their presence or absence was highly correlated. To test for other similarities, neurons exhibiting both responses were subjected to various procedures. On 29 cells, the membrane potential was displaced by steady depolarizing or hyperpolarizing current injected through the recording electrode. In all cells tested, the depolarizing responses induced by NE and by explant stimulation were affected in the same way by this test. The response was increased in amplitude by depolarizing and decreased by hyperpolarizing current injections (Fig. 5). This relationship of the response to membrane potential is the one expected if the response is caused or accompanied by an increased input resistance, and this possibility was tested in 10 cells. Constant current pulses were passed through the recording electrode during stable control periods and during depolarizations evoked by NE application (eight cells). Similar tests were made during depolarizations evoked by explant stimulation (four cells), though this was more difficult because of the shorter duration of these responses. It was observed from these tests that input resistance was increased during both the NE and the stimulation-induced depolarizations $(16.7 \pm 5.5 \%$, mean $\pm \mathrm{SD}, n=10)$. An example of this observation is shown in Fig. 6 .

On 12 occasions (cells showing depolarizing responses to NE and to explant stimulation), the response to stimulation was tested during a depolarization resulting from NE application. In each case, it was noted that the response to stimulation was smaller during the NE-induced depolarization than during a control period, and it sometimes appeared to be completely abolished (Fig. 7). In four of these cells, the possibility that the diminished response could result from the depolarized membrane potential was tested by observing the response to explant stimulation during comparable depolarizations by injected current. However, it was found that the responses were not decreased by these current injections (not shown).

In order to test whether the depolarizing responses were mediated by NE, we applied desmethylimipramine (DMI), which blocks reuptake of NE into noradrenergic nerve terminals, and various adrenergic receptor antagonists. DMI was applied at a concentration of $5 \mu \mathrm{M}$, by pressure, to over 20 neurons which exhibited depolarizing responses to explant stimulation. In most of these, there was some response to the DMI application itself, usually a hyperpolarization, but on a few occasions, a depolarization resulted. Of these tests, rather clear increases in the responses of the neuron to explant stimulation were observed on four occasions. An example of these tests in which the response to NE application was also tested is shown in Fig. 8. In some cases, the magnitude of the response to DMI prevented detection of effects on the response to explant stimulation. In most of the remaining cells, no effect on this response was observed with DMI, though in two cells it was reduced.

The $\beta$-adrenergic receptor blocker, propranolol, was tested on nine cells showing responses to explant stimulation and/or NE application. Propranolol also had a direct effect on most neurons when applied by pressure $(1 \mu \mathrm{M})$, usually a small hyperpolarization, but on two occasions, a depolarization. The effects on responses to explant stimulation and $\mathrm{NE}$ application were mixed. In three cells, there was a reduction of stimulationevoked depolarization, and in one of these, a depolarizing response to NE was blocked. In the remaining tests, propranolol appeared to have no effect on the responses. 


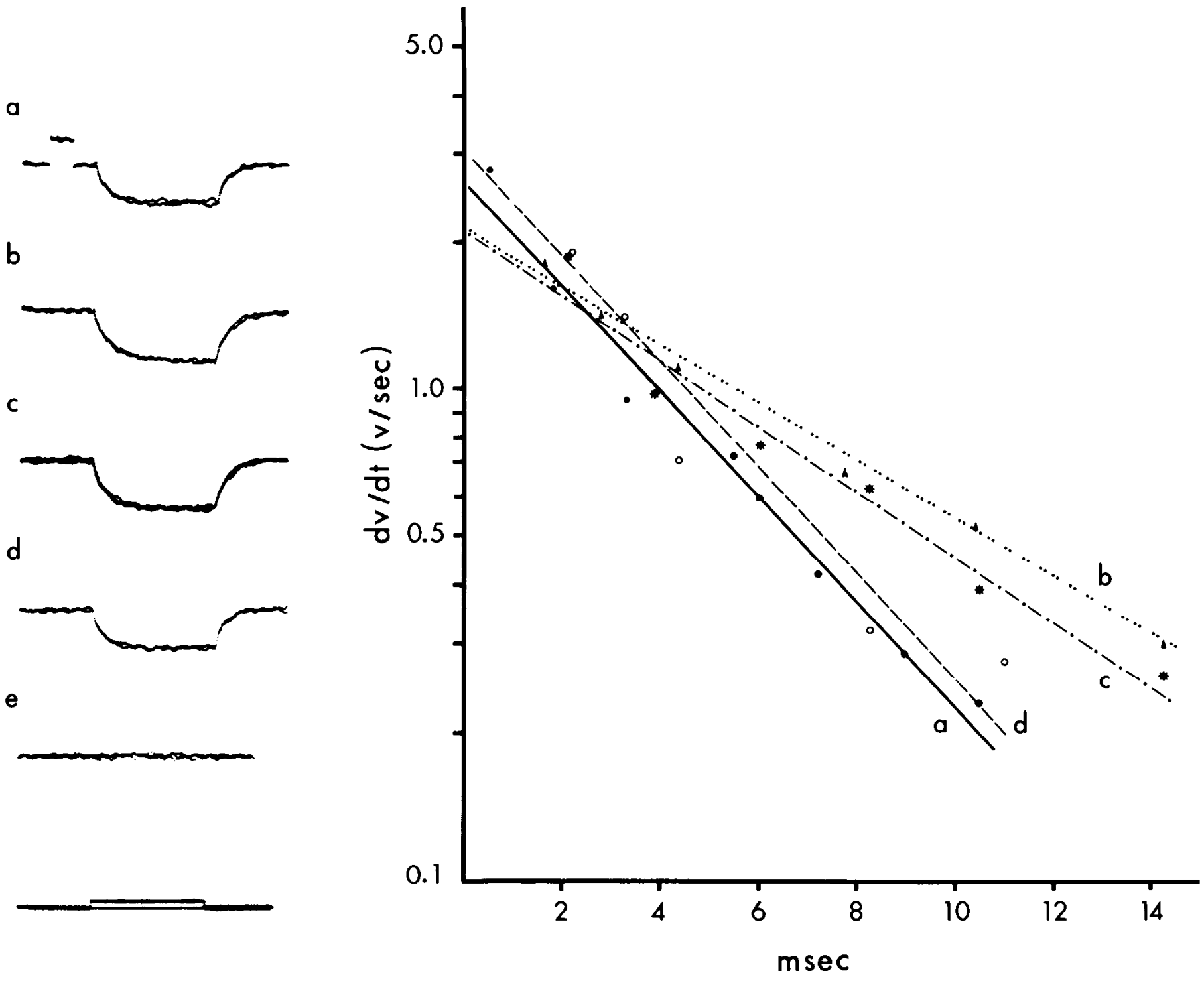

Figure 6. Measurement of input resistance of a cell during depolarizing responses. Left, Oscilloscope tracings of voltage recordings to a hyperpolarizing current pulse (bottom trace) at various stages of the study. The right-hand graph is a plot of time versus rate of change of voltage on the downward slope of the voltage transient. Letters next to the straight lines correspond to the various voltage transient tracings. $a$, Before explant stimulation and drug application ( ; time constant, $4 \mathrm{msec}) ; b$, during response evoked by explant stimulation ( $\Delta$; time constant, 7.2 msec); $c$, during response to iontophoretically applied NE (*; time constant, 6.6 msec); $d$, after study (O; time constant, 4 msec). Roth the amplitude of the voltage transient and the time constants were larger during the evoked responses when compared to the controls $(a$ and $d$ ), indicating an increase in input resistance of the membrane during the depolarizing responses. $e$, Voltage recording after the electrode was pulled out of the cell. The points were fitted by the method of least squares (coefficient of correlations were: $a, 0.99 ; b, 0.99 ; c, 0.98 ; d, 0.95$. Calibration pulse, $10 \mathrm{mV}, 10 \mathrm{msec}$ ). This increase in input resistance was not related to rectification of the membrane. Depolarization of the membrane to a more positive potential by injection of depolarizing current did not alter the input resistance of the membrane for this cell (data not shown).

Much more consistent results were obtained using $\alpha$-adrenergic receptor blockers. Phenoxybenzamine was tested on three cells (two by iontophoretic application, one by $1 \mu \mathrm{M}$ pressure) and phentolamine was tested by pressure $(1 \mu \mathrm{M})$ on one cell. In each case, the depolarizing response to NE application was completely blocked, while the depolarizing response to explant stimulation was blocked in one and reduced in the other three cells. In two of these cells, however, increased threshold to spike generation was observed, and great care was necessary to demonstrate the depolarization blockade in the absence of this effect. Piperoxan appeared to be devoid of this property of elevating spike thresholds in the concentration used ( $50 \mu \mathrm{M}$ by pressure), and was almost equally effective in blocking the depolarizing responses to explant stimulation and to iontophoretically applied NE. An example of one of the seven cells tested is shown in Fig. 9. This cell showed rather complete and reversible blockade of both types of depolarizing response in the absence of any increase in threshold for spike generation; in fact, a small decrease in this threshold was observed during the piperoxan test. Antagonism was observed on all seven cells investigated.

Hyperpolarizing responses. Most attention was focused on the slow depolarizing responses becasue of the clear correlation between their presence and the catecholamine innervation from the explants. The hyperpolarizing responses were tested on 13 occasions by observing the amplitude of the membrane potential deflection due to passage of a hyperpolarizing current pulse. On nine cells, no apparent change in the input resistance of the membrane was observed. On three occasions, an increase in the input resistance was noted $(31.3 \pm 2.4 \%$; mean $\pm \mathrm{SD})$. The remaining cell showed a decrease in input resistance. These results indicate that the hyperpolarizing responses were accom- 
Figure 7. Effects of NE on depolarizing responses to explant stimulation. Left, Chart recordings of responses elicited by stimulation of the explant ( $C O N$ TROL). NE applied by a perfusion pipette depolarized the membrane by about $6 \mathrm{mV}$ during which the evoked response to explant stimulation was abolished (NOREPINEPHRINE).
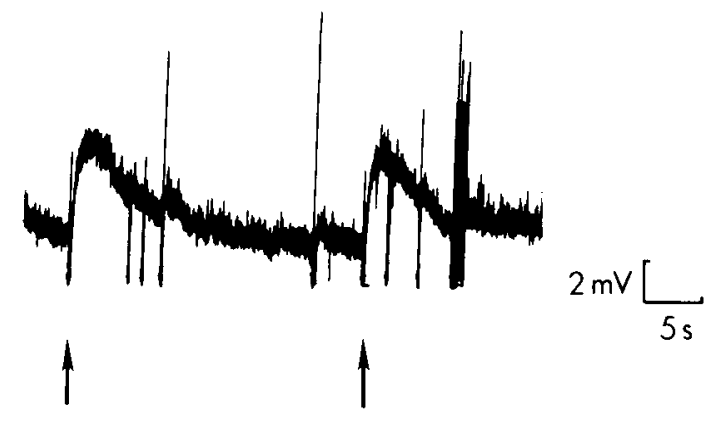
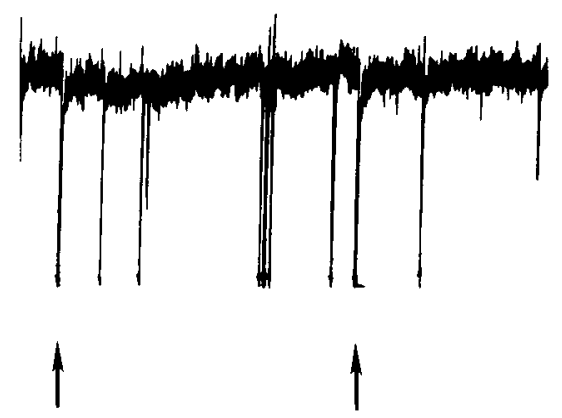

panied by an increase or no change in membrane resistance of the target cell. A similar conclusion was drawn from results obtained on the effects of injected hyperpolarizing and depolarizing currents to the evoked responses examined on several cells.

Propranolol was tested on two cells exhibiting hyperpolarizing responses to NE. The response of one was reduced by propranolol while the other cell was unaffected. The hyperpolarizing phase of a biphasic response to explant stimulation was unaffected in one other cell tested with propranolol.

\section{Discussion}

The objectives of the experiments described were to determine whether a "pathway" from the LC to a remote target area could be established in culture, and whether such a substrate could be used to elucidate the actions and mechanism of synaptically released NE. It would appear that the attempt has been successful, at least in part, since reproducible responses of the spinal neurons to stimulation of an LC-containing explant have been observed, and data pertaining to the transmitter identity and actions have been obtained.

It is of interest to relate our observations from this study to those reported from animal experiments. Most investigations of NE actions on spinal neurons have depended on extracellular studies, so that direct comparisons are not possible. However, the observed responses of depressions, longer duration excitations, and biphasic depression/excitations are correlated with the types of responses we have seen (see Marshall, 1983, for a review). A difference is found in the frequency with which the different types of response are observed. In animal studies, depressant responses of spinal neurons to NE have been reported much more frequently than excitatory ones, whereas in our co-cultures, depolarizing responses are more frequent than hyperpolarizing ones. Intracellular recordings of NE responses in spinal motoneurons have demonstrated that the responses are hyperpolarizations (Phillis et al., 1968; Engberg and Marshall, 1971) very similar to those reported in this study. In a recent study of facial nucleus motoneurons with intracellular recording, depolarizing responses to NE were observed which were very similar to the ones reported herein, both with respect to time course and an accompanying increase in membrane resistance (Vander Maelen and Aghajanian, 1980).

It should be pointed out that, with the exception of dorsal root ganglion cells, which have a rather distinctive appearance, the functional type of spinal neurons in dissociated cultured is not identifiable. Most cells recorded from were medium sized spinal neurons $(<30 \mu \mathrm{m})$ and probably were not $\alpha$-motoneurons.-

In the few electrophysiologic studies of the coeruleo-spinal pathway in animals, depressions of neuronal activity have been reported by Pearson et al. (1978) and Hodge et al. (1981), while
Strahlendorf et al. (1980) observed facilitations. In an intracellular study of motoneurons, Fung and Barnes (1981) reported facilitations and EPSPs evoked by LC stimulation. In view of our results, it seems possible that either excitatory or depressant responses of spinal neurons may result from LC stimulation, and that the preponderance of one or the other type of response may depend on experimental variables such as anesthesia and dosage of NE (see Szabadi, 1979; Armstrong-James and Fox, 1983). Whether the high divalent cation concentrations used in these experiments (up to $14 \mathrm{~mm}$ ) altered the sensitivity of the ionic channels and receptors mediating these responses, the release of $\mathrm{NE}$, is not known.

Because the brain stem explant undoubtedly contained not only LC but other types of neurons, it is necessary to consider the possibility that the responses observed were mediated by some transmitter other than NE. Our suggestion that the depolarizing responses to explant stimulation are noradrenergic is based mainly on the great similarity between these responses and responses to locally applied NE in the same neuron. The parallel time courses and responses to depolarizing and hyperpolarizing current injections indicate very similar mechanisms. The very high correlation between the presence of the depolarizing responses to $\mathrm{NE}$ and to explant stimulation in a given neuron suggests a common receptor or mechanism which is absent in nonresponding neurons. The absence of the depolarizing responses in a series of experiments in which the explant did not contain catecholamine-containing cells is also suggestive of this relationship. The ability of locally applied NE to diminish or block the response to explant stimulation might be interpreted as the result of a competition for receptors by locally and synaptically released NE. Alternatively, the locally released $\mathrm{NE}$ could be inhibiting synaptic release of $\mathrm{NE}$ by acting on presynaptic "autoreceptors" on noradrenergic axon terminals (e.g., Langer, 1977).

Finally, the action of $\alpha$-adrenergic antagonists in blocking the depolarizing responses argues for mediation by $\alpha$-adrenergic receptors. Although the depolarizing responses to explant stimulation were blocked to a lesser extent by phenoxybenzamine and phentolamine than the NE-induced depolarizations, piperoxan seemed almost equi-effective on the two types of response. It is interesting that facial motoneurons respond to NE application with a slow depolarization accompanied by an increase in input resistance, and that this response, which strongly resembles the ones we report, is blocked by piperoxan (Vander Maelen and Aghajanian, 1980). In addition, White and Neuman (1983) have recently reported that the facilitation of spinal motoneurons by NE is blocked by $\alpha$-antagonists, though an absolute specificity was not demonstrated. By itself, no one of the above observations provides compelling evidence that the depolarizing responses to the explant stimulation are mediated by NE. However, we feel that the several observations 


\section{Control}
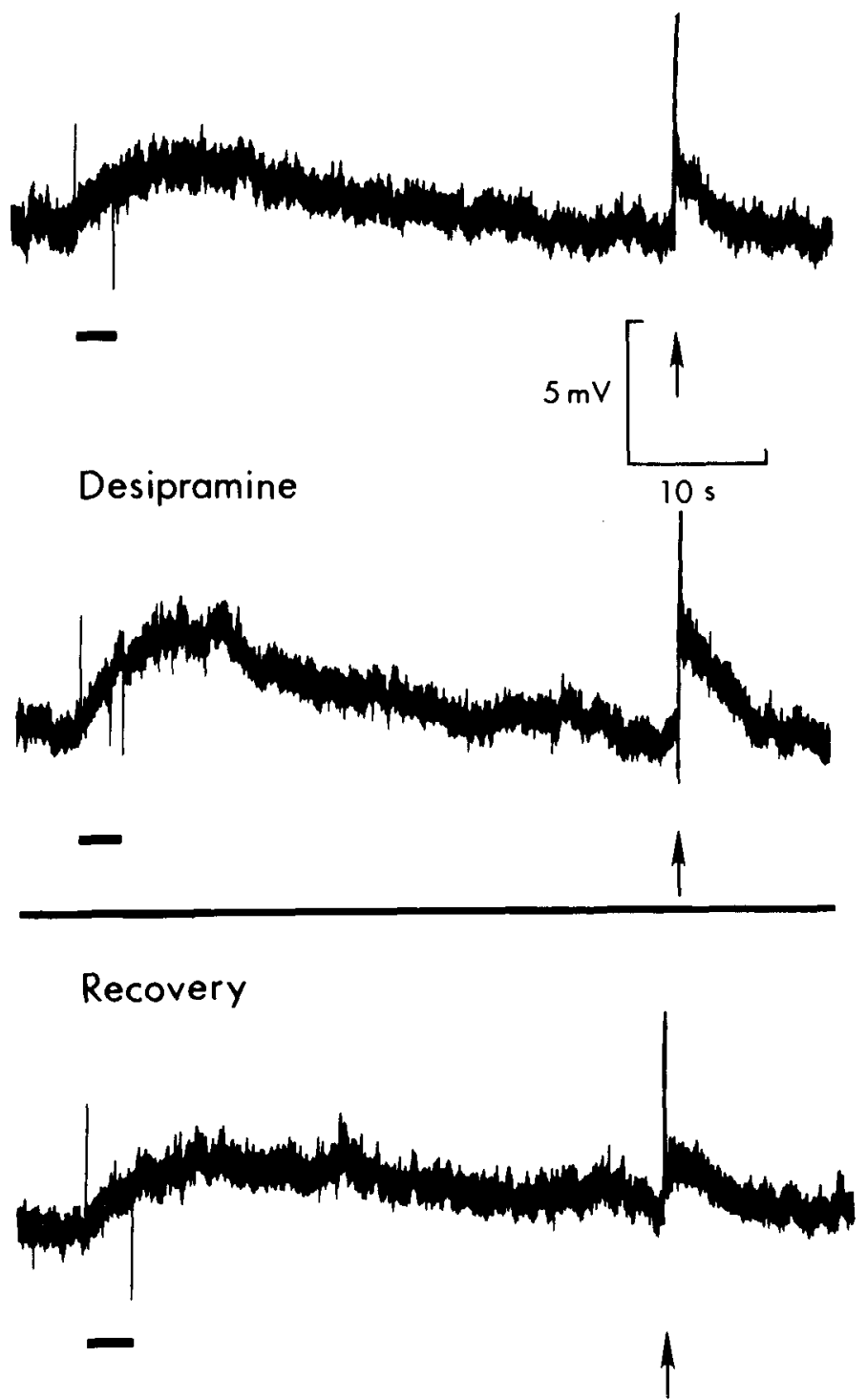

Figure 8. Effects of the neuronal uptake blocker of NE desmethyl imipramine (Desipramine) on evoked responses to iontophoretically applied NE (solid bars) and explant stimulation (arrows). Top trace shows chart recordings of control responses. During perfusion of DMI ( $5 \mu \mathrm{M}$, continuous line), the evoked responses were greatly potentiated. Responses returned to about control size after the application of DMI had been terminated.

of similarity or interaction of the responses to NE application and to explant stimulation strongly indicate that this is the case. The reason for the lack of consistent potentiation of the NE and stimulation-evoked depolarizations by desmethylimipramine is not clear. It may be that the large volume of bathing medium surrounding the spinal neurons, compared to the limited extracellular space in vivo, renders diffusion a more important factor than neuronal reuptake for the termination of NE action. In this case, reuptake inhibitors would be expected to be less effective than in vivo. It has also been reported that the tricyclic anti-depressants have some $\alpha$-receptor blocking capability (Bradshaw, et al., 1974; Bevan et al., 1978, U'Prichard et al., 1978), a feature which could confound the effects of reuptake blockade. Indeed, under conditions where the uptake mechanism was effectively blocked, potentiation of excitatory responses to $\mathrm{NF}$ on cortical neurons was not always
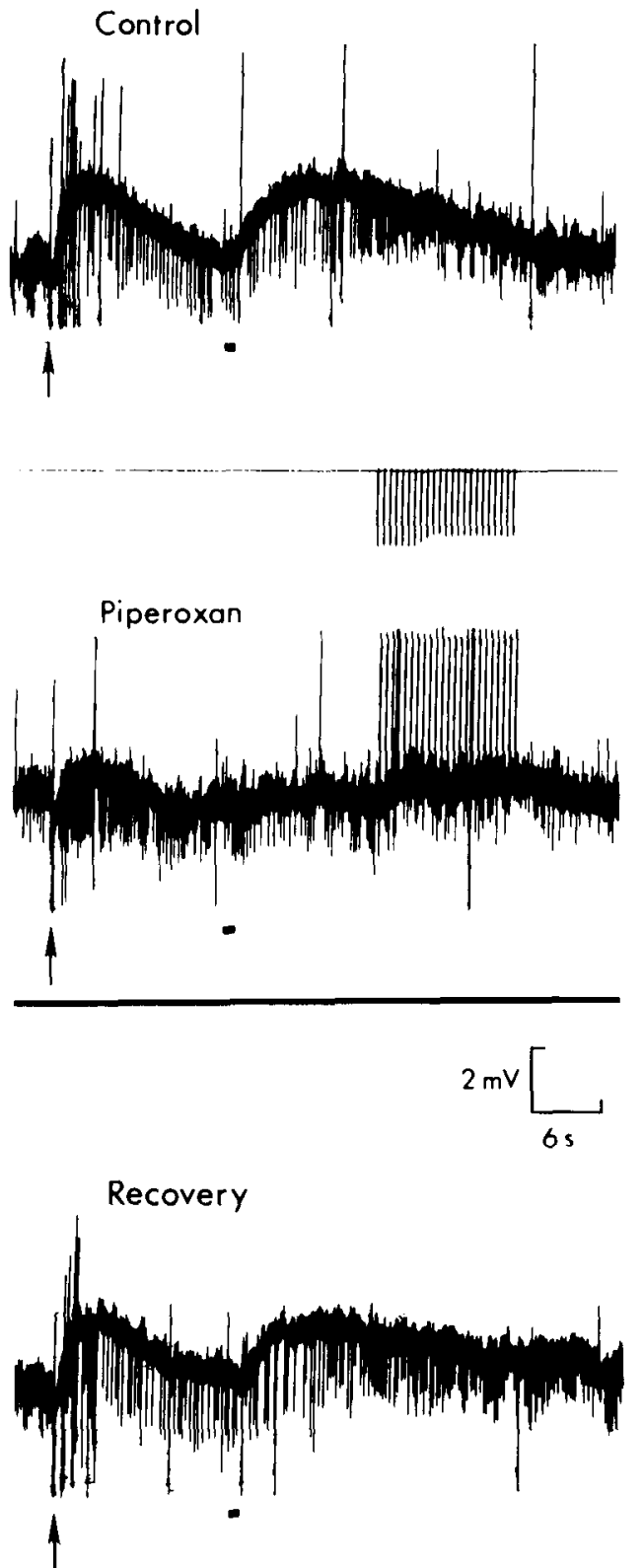

Figure 9. Effects of the $\alpha$-antagonist piperoxan on neuronal responses to explant stimulation (arrows) and iontophoretically applied NE (solid bars). The top trace shows chart recordings of control responses. During the perfusion of piperoxan $(50 \mu \mathrm{M}$, continuous dark line), the cvoked responses were antagonized. Spike threshold (measured as minimum current necessary to elicit an action potential, shown as downward deflection on second thin line) was actually reduced in the presence of piperoxan. Recovery of the responses was obtained several minutes following the termination of application of piperoxan.

observed. The lack of potentiation was suggested to be due to a balance between the antagonistic effect of DMI at $\alpha$-receptor sites and its uptake blockade action (Bevan et al., 1978).

One possibility not addressed in the above arguments is that the depolarizing responses are mediated by a catecholamine similar to NE. Though this option seems less likely to us, it should be considered, since reasonably high levels of dopamine have been reported in LC cultures and their bathing medium (Schlumpf et al., 1977, Hendelman et al., 1982).

The mechanism of the depolarization is of considerable interest. Similar responses, i.e., a slow, long lasting depolarization accompanied by a decreased membrane conductance, have been 
observed with application of various substances to central neurons, e.g., acetylcholine on cortical neurons (Krnjevic et al., 1971), substance $\mathrm{P}$, and muscarine on cultured spinal neurons (Nowak and MacDonald, 1982, 1983), but we are not aware of other examples of synaptically generated responses of this kind in the mammalian central system. If the depolarization is generated by a decreased ionic conductance, the ion or ions involved must have an equilibrium potential at a value more negative than the membrane potential. Either potassium or chloride ion could satisfy this requirement, and we have not yet attempted to identify experimentally which of these is responsible. In other instances, however, a decreased conductance to potassium ions has been identified as the mechanism of such slow depolarizations (Krnjevic et al., 1971; Nowak and MacDonald, 1982, 1983). In the latter two studies, it has been suggested that the depolarizations may be generated by blocking of a voltage- and time-dependent potassium current referred to as M-current (Brown and Adams, 1980).

Although most attention was given to the depolarizing responses, the hyperpolarizing responses to NE application are also of considerable interest. The data indicate that there was a higher incidence of hyperpolarizing responses to NE in those cells which exhibited a hyperpolarizing response to explant stimulation than in those giving a depolarizing or no response. We have less direct evidence that these responses are true noradrenergic responses; however, they are very similar to actions of NE reported from intracellular studies in animals, i.e., a hyperpolarization accompanied by a decrease or no observable change in input resistance (Engberg and Marshall, 1971; Siggins et al., 1971b). 'I'he possible mechanisms of such responses have been discussed by Marshall and Engberg (1979) and Marshall (1983). If these hyperpolarizing responses are also noradrenergic, it seems most likely that the depolarizing and hyperpolarizing responses are mediated by different receptors. Most studies of noradrenergic function in central neurons in which receptor types have been identified indicate that hyperpolarizations are usually mediated by $\beta$-receptors while depolarizations are associated with $\alpha$-receptors. Some exceptions to this pattern are seen in the hyperpolarizations of LC neurons, apparently mediated by $\alpha_{2}$-receptors (Aghajanian and Vander Maelen, 1982) and a study in the hippocampus which suggests excitations through $\beta$-receptors and depressions through $\alpha$-receptors (Mueller et al., 1982).

The very high incidence of depolarizing responses to NE in spinal neurons which were depolarized by explant stimulation suggests a selective interaction between the explant and the spinal neurons. Since the depolarizing responses were observed much less frequently in cultures of spinal neurons with no explant, it is possible that the receptors mediating the depolarizing response are either absent or masked in such cultures. Because of the lower density of spinal neurons observed close to the explant, another possibility is that the explant effects a selectively toxic influence on spinal neurons not possessing the mechanism for generation of the depolarizing response.

If the first possibility is correct, it suggests that some component in the explant (presumably the catecholamine-containing cells) is capable either of unmasking or inducing synthesis of the receptors responsible for the depolarization, or perhaps of effecting a conversion of one receptor type to another. The possibility of interconversion of $\alpha$ - and $\beta$-receptors has recently been discussed by Kunos $(1976,1980)$. The induced appearance of $\alpha$-adrenergic receptors in association with noradrenergic innervation has been indicated in studies of adrenergic receptors. Deskin et al. (1981) found that development of an $\alpha$ receptor-mediated process, incorporation of inorganic phosphate into phospholipids, progressed in parallel with development of presynaptic innervation as measured by the synaptosomal uptake of catecholamines, and was prevented by neonatal lesions of the catecholamine systems with 6-hydroxydopamine. Crutcher and Davis (1980) observed that the distribution of $\alpha$ receptors in the hippocampus corresponded to the regions most densely innervated by the noradrenergic system, whereas the $\beta$-receptors were diffusely distributed throughout the hippocampus. The time course of the ontogenetic development of $\beta$ receptors, however, appears independent of the noradrenergic innervation (Harden et al., 1977). If the development of $\alpha$ receptors on spinal neurons in our co-cultures is dependent on the presence of noradrenergic innervation, the high proportion of depolarizing responses in the co-cultures relative to cultures containing spinal cord alone would be explained.

\section{References}

Aghajanian, G. K., and C. P. Vander Maelen (1982) $\alpha_{2}$-Adrenoceptor mediated hyperpolarization of locus coeruleus neurons: Intracellular studies in vivo. Science 215: 1394-1396.

Amaral, D. G., and H. M. Sinnamon (1977) The locus coeruleus: Neurobiology of a central noradrenergic nucleus. Prog. Neurobiol. 9: 147-196.

Armstrong-James, M., and Fox, K. (1983) Effects of iontophoresed noradrenaline on the spontaneous activity of neurones in the rat primary somatosensory cortex. J. Physiol. 335: 427-447.

Bevan, P., C. M. Bradshaw, R. Y. K. Pun, N. T. Slater, and E. Szabadi (1978) Comparison of the responses of single cortical neurones to tyramine and noradrenaline: Effects of desipramine. Br. J. Pharmacol. 63: 651-657.

Bloom, F. E., and E. L. F. Battenberg (1976) A rapid, simple and sensitive method for demonstration of central catecholamine-containing neurons and axons by glyoxylic acid-induced fluorescence. II. A detailed description of methodology. J. Histochem. Cytochem. 24: $561-571$.

Bradshaw, C. M., M. H. T. Roberts, and E. Szabadi (1974) Effects of imipramine and desipramine on responses of single cortical neurones to noradrenaline and 5-hydroxytryptamine. Br. J. Pharmacol. 52: 349-358.

Brown, D. A., and P. R. Adams (1980) Muscarinic suppression of a novel voltage-sensitive $\mathrm{K}^{+}$current in a vertebrate neurone. Nature (Lond.) 283: 673-676.

Commissiong, J. W. (1981) Evidence that the noradrenergic coeruleospinal projection decussates at the spinal level. Brain Res. 212: 145151.

Commissiong, J. W., S. O. Hellstrom, and N. H. Neff (1978) A new projection from locus coeruleus to the spinal ventral columns: Histochemical and biochemical evidence. Brain Res. 148: 207-213.

Crutcher, K. A., and J. N. Davis (1980) Hippocampal $\alpha$ - and $\beta$ adrenergic receptors: comparison of $\left[{ }^{3} \mathrm{H}\right]$ dihydroalprenolol and $\left[{ }^{3} \mathrm{H}\right]$ WB 4101 binding with noradrenergic innervation in the rat. Brain Res. 182: 107-117.

Deskin, R., F. J. Seidler, W. L. Whitmore, and T. A. Slotkin (1981) Development of $\alpha$-noradrenergic and dopaminergic receptor systems depends on maturation of their presynaptic nerve terminals in the rat brain. J. Neurochem. 36: 1683-1690.

Dreyfus, C. F., M. D. Gershon, and S. M. Crain (1979) Innervation of hippocampus by co-cultured central adrenergic neurons from fetal mouse brainstem. Brain Res. 161: 431-445.

Engberg, I., and K. C. Marshall (1971) Mechanism of noradrenaline hyperpolarization in spinal cord motoneurones of the cat. Acta Physiol. Scand. 83: 142-144.

Foote, S. L., F. E. Bloom, and G. Aston-Jones (1983) Nucleus locus coeruleus: New evidence of anatomical and physiological specificity. Physiol. Rev. 63: 844-914.

Fung, S. J., and C. D. Barnes (1981) Evidence of facilitatory coeruleospinal action in lumbar motoneurons of cats. Brain Res. 216: 299311.

Harden, T. K., B. B. Wolfe, J. R. Sporn, B. K. Poulos, and P. B. Molinoff (1977) Effects of 6-hydroxydopamine on the development of the beta adrenergic receptor/adenylate cyclase systems in rat cerebral cortex. J. Pharmacol. Exp. Ther. 203: 132-143.

Hendelman, W. J., K. C. Marshall, R. Ferguson, and S. Carriére (1982) Catecholamine neurons of the central nervous system in organotypic culture. Dev. Neurosci. 5: 64-76.

Hodge, C. J., Jr., A. V. Apkarian, R. Stevens, G. Vogelsang, and H. J. 
Wisnicki (1981) Locus coeruleus modulation of dorsal horn unit responses to cutaneous stimulation. Brain Res. 204: 415-420.

Krnjevic, K., R. Pumain, and L. Renaud (1971) The mechanism of excitation by acetylcholine in the cerebral cortex. J. Physiol. (Lond.) 215: $247-268$

Kunos, G. (1976) Adrenoceptors. Annu. Rev. Pharmacol. Toxicol. 18: $291-311$.

Kunos, G. (1980) Reciprocal changes in $\alpha$ - and $\beta$-adrenoceptor reactivity-myth or reality. Trends Pharmacol. Sci. 1: 282-284.

Langer, S. Z. (1977) Presynaptic receptors and their role in the regulation of transmitter release. Br. J. Pharmacol. 60: 481-497.

Marshall, K. C. (1983) Catecholamines and their actions in the spinal cord. In Handbook of the Spinal Cord, R. A. Davidoff, ed., Vol. 1: Pharmacology, pp. 275-328, Marcell Dekker, New York.

Marshall, K. C., and I. Engberg (1979) Reversal potential for noradrenaline-induced hyperpolarization of spinal motoneurons. Science 205 ; 422-424.

Marshall, K. C., and C. B. Garber (1983) Effects of locus coeruleus lesions on trasmitter responses of Purkinje neurons in combined cerebellum-brainstem explant cultures. Soc. Neurosci. Abstr. 9: 1000.

Marshall, K. C., R. Y. K. Pun, W. J. Hendelman, and P. G. Nelson (1981) A coeruleo-spinal system in culture. Science 213: 355-357.

Mueller, A. L., M. R. Palmer, B. J. Hoffer, and T. V. Dunwiddee (1982) Hippocampal noradrenergic responses in vivo and in vitro: Characterization of alpha and beta components. Naunyn-Schmiedeberg's Arch. Pharmacol. 318: 259-266.

Nowak, L. M., and R. L. MacDonald (1982) Substance P: Ionic basis for depolarizing responses of mouse spinal cord neurons in cell culture. J. Neurosci. 2: 1119-1128.

Nowak, L. M., and R. L. MacDonald (1983) Ionic mechanism of muscarinic cholinergic depolarization of mouse spinal cord neurons in cell culture. J. Neurophysiol. 49: 792-803.

Nygren, L. G., and L. Olson (1977) A new major projection from locus coeruleus: The main source of noradrenergic nerve terminals in the ventral and dorsal columns of the spinal cord. Brain Res. 132: 8593.

Olson, L., T. Ebendal, and A. Seiger (1979) NGF and anti-NGF. Evidence against effects on fiber growth in locus coeruleus from cultures of perinatal CNS tissue. Dev. Neurosci. 2: 160-176.

Peacock, J. H., P. G. Nelson, and M. W. Goldstone (1973) Electrophysiologic study of cultured neurons dissociated from spinal cords and dorsal root ganglia of fetal mice. Dev. Biol. 30: 137-152.

Pearson, J. A., D. E. Taylor, and D. M. Janzen (1978) An inhibitory pathway from locus coeruleus to the spinal cord of the rat. Proc. Can. Fed. Biol. Soc. 21: 55.

Phillis, J. W., and G. K. Kostopoulos (1977) Activation of a noradrenergic pathway from the brain stem to rat cerebral cortex. Gen. Pharmacol. 8: 207-211.

Pun, R. Y. K., K. C. Marshall, S. Fitzgerald, P. B. Guthrie, and P. G. Nelson (1981) Noradrenergic system in culture: an electrophysiological study. Soc. Neurosci. Abstr. 7: 570.

Ransom, B. R., E. Neale, M. Henkart, P. N. Bullock, and P. G. Nelson
(1977) Mouse spinal cord in cell culture. I. Morphology and intrinsic neuronal electrophysiologic properties. J. Neurophysiol. 40: 1132 1150.

Rogawski, M. A., and G. K. Aghajanian (1982) Activation of lateral geniculate neurons by locus coeruleus or dorsal noradrenergic bundle stimulation: Selective blockade by the alpha ${ }_{1}$-adrenoceptor antagonist prazosin. Brain Res. 250: 31-39

Sasa, M., K. Munekiyo, H. Ikeda, and S. Takaori (1974) Noradrenaline mediated inhibition by locus coeruleus of spinal trigeminal neurons. Brain Res. 80: 443-460.

Satoh, K., M. Tokyama, K. Yamamoto, T. Sakumoto, and N. Shimizie (1977) Noradrenaline innervation of the spinal cord studied by the horseradish peroxidase method combined with monoamine oxidase staining. Exp. Brain Res. 30: 175-186

Schlumpf, M., W. J. Shoemaker, and F. E. Bloom (1977) Explant cultures of catecholamine-containing neurons from rat brain: Biochemical, histofluorescence, and electron microscopic studies. Proc. Natl. Acad. Sci. U. S. A. 74: 4471-4475.

Segal, M., and F. E. Bloom (1974) The action of norepinephrine in the rat hippocampus. II. Activation of the input pathway. Brain Res. 72: 99-114.

Siggins, G. R., B. J. Hoffer, A. P. Oliver, and F. E. Bloom (1971a) Activation of a central noradrenergic projection to cerebellum. $\mathrm{Na}$ ture 233: 481-483.

Siggins, G. R., A. P. Oliver, B. J. Hoffer, and F. E. Bloom (1971b) Cyclic adenosine monophosphate and norepinephrine: Effects on transmembrane properties of cerebellar Purkinje cells. Science 171: 192-194.

Strahlendorf, J. C., H. K. Strahlendorf, R. E. Kingsley, J. Gintautas, and C. D. Barnes (1980) Facilitation of the lumbar monosynaptic reflexes by locus coeruleus stimulation. Neuropharmacology 19: 225230.

Szahadi, E. (1979) Adrenoceptors on central neurones: microelectrophoretic studies. Neuropharmacology 18: 831-843.

U'Prichard, D. C., D. A. Greenberg, P. P. Sheehan, and S. H. Snyder (1978) Tricyclic antidepressants: Therapeutic properties and affinity for $\alpha$-noradrenergic receptor binding sites in the brain. Science 199 : 197-198.

Vander Maelen, C. P., and G. K. Aghajanian (1980) Intracellular studies showing modulation of facial motoneurone excitability by serotonin. Nature 287: 346-347.

Victorov, I., Nguyen-Legros, J. M. Boutry, M. Gay, B. Berger, and J. J. Hauw (1978) Culture des tissus: Technique simple de culture du noyau de locus coeruleus du Souriceau nouveau-né. C. R. Hebd. Seance. Acad. Sci. (Paris) 286: 1893-1895.

Westlund, K. N., and J. D. Coulter (1980) Descending projections of the locus coeruleus and subcoeruleus/medial parabrachial nuclei in monkey: Axonal transport studies and dopamine- $\beta$-hydroxylase immunocytochemistry. Brain Res. Rev. 2: 235-264.

White, S. R., and R. S. Neuman (1983) Pharmacological antagonism of facilitatory but not inhibitory effects of serotonin and norepinephrine on excitability of spinal motoneurons. Neuropharmacology 22 : 489-494. 